\title{
The prognostic value of copeptin for acute intracerebral hemorrhage patients
}

\author{
AIMEI ZHANG ${ }^{1}$, JUN LI $^{2}$, XIAOYUN LI ${ }^{1}, \mathrm{LI} \mathrm{SONG}^{1}$ and HONGFANG LI ${ }^{1}$ \\ ${ }^{1}$ Department of Neurology, Affiliated Hospital of Ji Ning Medical University, Jining 272029; \\ ${ }^{2}$ Graduate School of Tianjin Medical University, Tianjin 300070, P.R. China
}

Received August 22, 2012; Accepted October 15, 2012

DOI: $10.3892 /$ etm.2012.804

\begin{abstract}
The aim of the current study was to examine the prognostic value of copeptin for acute intracerebral hemorrhage (ICH) patients. A total of 120 patients were recruited. The plasma copeptin levels were measured using sandwich immunoassays. The hematoma volume, Glasgow coma scale (GCS) and ICH score were evaluated. The 90-day functional outcomes were measured with the modified Rankin scale (mRS). Copeptin correlated positively with hematoma volume $(\mathrm{r}=0.61, \mathrm{P}=0.000)$, Hemphill scores $(\mathrm{r}=0.78, \mathrm{P}=0.000)$ and white blood cell counts $(\mathrm{r}=0.58, \mathrm{P}=0.000)$, whereas copeptin correlated negatively with GCS scores $(r=-0.79, \mathrm{P}=0.000)$. Copeptin levels were also higher in patients with an unfavorable functional outcome at 90 days than in patients with a favorable outcome $(4.14 \pm 0.87$ vs. $3.09 \pm 0.30 \mathrm{ng} / \mathrm{ml}$; $\mathrm{t}=8.001$, $\mathrm{P}=0.00)$. Monovariate logistic regression analysis results suggest that copeptin is a predictor of the 90-day functional outcomes of $\mathrm{ICH}$ patients $(\mathrm{OR}=3.17$, 95\% CI 2.01-4.35, $\mathrm{P}=0.003$. Multivariate logistic regression analysis results indicate that copeptin is an independent predictor of the 90-day functional outcomes of ICH patients.
\end{abstract}

\section{Introduction}

Cerebral hemorrhage is a serious disease that has high disability and mortality rates (1-3). Therefore, an indicator that is closely associated with clinical manifestations, that may be measured quickly and gives a good prediction of the mortality rate, would be beneficial in the early prognosis of cerebral hemorrhage. Currently, it is considered that cerebral hemorrhage-related hematoma formation $(4,5)$, increased bleeding and persistent hypertension are associated with early neurological degeneration and poor prognosis (6).

Correspondence to: Dr Aimei Zhang, Department of Neurology, Affiliated Hospital of Ji Ning Medical University, 79 Guhai Road, Jining 272029, P.R. China

E-mail: aimeizhang@yahoo.cn

Key words: copeptin, intracerebral hemorrhage, prognostic value
Arginine vasopressin (AVP), which is one of the most important stress hormones, is a bioactive peptide with nine amino acid residues, that is produced by the hypothalamus (7). However, when AVP is released into the blood in pulse mode, it is extremely unstable with a short biological half-life. Thus, the clinical application of AVP measurement is limited. Copeptin $(5 \mathrm{kDa})$ is the 39 -amino acid carboxy-terminal domain of pro-AVP, which includes a leucine-rich core fragment. AVP and copeptin are released equally in the body, thus the direct measurement of AVP may be replaced by the measurement of copeptin (8). Copeptin is important in the maturation, transportation and intracellular processing of AVP and it enables the misfolded monomers to re-fold, to ensure the stability of its biological effects (9).

Copeptin levels are considered to reflect the severity and prognosis of a variety of diseases. Jochberger et al (10) compared the serum copeptin levels of 70 healthy individuals with those of 157 intensive care unit (ICU) patients within $24 \mathrm{~h}$ of cardiac surgery and identified that the copeptin levels of the ICU group were significantly higher than those of the healthy individuals. Neuhold et al (11) performed a 1-year follow-up of 786 patients with various stages of heart failure and revealed that copeptin was the most effective predictor of mortality in New York Heart Association (NYHA) stage II and III patients. Voors et al (12) completed a 2-year follow-up of 224 patients and identified that copeptin was an effective prognostic indicator of heart failure following acute myocardial infarction (AMI); it was found to be more effective than the currently accepted indicators, B-type natriuretic peptide (BNP) and amino-terminal B-type natriuretic peptide (NT-proBNP).

In the current study, copeptin was identified to be significantly elevated in the serum of acute cerebral hemorrhage patients and the levels of copeptin increased as the amount of bleeding and cerebral hemorrhage worsened. Logistic regression analysis revealed that copeptin level, Glasgow coma scale (GCS) score and Hemphill score were independent indicators in the evaluation of impaired 90-day nerve function following cerebral hemorrhage.

\section{Materials and methods}

Patients. A total of 120 patients with acute intracerebral hemorrhage $(\mathrm{ICH})$ were enrolled, including 76 males and 
Table I. General clinical data of the patients in this study.

\begin{tabular}{|c|c|c|c|c|c|}
\hline Variable & $\mathrm{n}=120$ & $\begin{array}{l}\text { High copeptin } \\
\text { group }(n=58)\end{array}$ & $\begin{array}{l}\text { Low copeptin } \\
\text { group }(n=62)\end{array}$ & Test value & P-value \\
\hline Male/total (\%) & $76(63 \%)$ & $32(55 \%)$ & $44(71 \%)$ & $1.78^{\mathrm{a}}$ & 0.075 \\
\hline Age (years) & $60 \pm 14$ & $60 \pm 13$ & $61 \pm 14$ & -0.59 & 0.554 \\
\hline Body temperature $\left({ }^{\circ} \mathrm{C}\right)$ & $36.4 \pm 0.5$ & $36.5 \pm 0.6$ & $36.4 \pm 0.4$ & 1.09 & 0.279 \\
\hline Systolic blood pressure (mmHg) & $175 \pm 32$ & $181 \pm 40$ & $169 \pm 22$ & 2.05 & 0.044 \\
\hline Diastolic blood pressure (mmHg) & $103 \pm 22$ & $101 \pm 22$ & $105 \pm 23$ & -0.92 & 0.362 \\
\hline White blood cell count (x10 $12 / 1)$ & $9.98 \pm 4.25$ & $11.59 \pm 4.82$ & $8.47 \pm 3.04$ & 4.25 & 0.000 \\
\hline Blood glucose (mM) & $6.63 \pm 2.41$ & $7.50 \pm 2.58$ & $5.81 \pm 1.96$ & 4.10 & 0.000 \\
\hline Hyponatremia (mM) & $142.38 \pm 7.53$ & $144.28 \pm 9.99$ & $140.61 \pm 3.55$ & 2.67 & 0.060 \\
\hline Hematoma volume (ml) & $57.46 \pm 46.76$ & $78.68 \pm 49.70$ & $37.60 \pm 34.50$ & 5.27 & 0.000 \\
\hline GCS score & $10.60 \pm 4.64$ & $6.86 \pm 3.62$ & $14.10 \pm 2.12$ & -13.39 & 0.000 \\
\hline Hemphill score & $2.05 \pm 1.62$ & $3.24 \pm 1.20$ & $0.94 \pm 1.08$ & 10.99 & 0.000 \\
\hline mRS score & $3.32 \pm 1.95$ & $4.79 \pm 1.23$ & $1.94 \pm 1.42$ & 11.75 & 0.000 \\
\hline
\end{tabular}

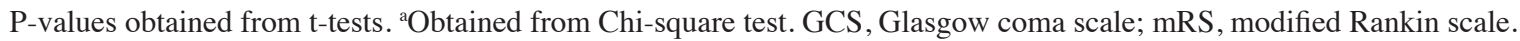

44 females. Sixty healthy individuals were selected as a control group. Prior written and informed consent was obtained from every patient and the study was approved by the ethics review board of Ji Ning Medical University (Shandong, China).

Clinical evaluation. The severity of ICH was assessed. The hematoma volume was calculated based on a brain computed tomography $(\mathrm{CT})$ scan with $\mathrm{ABC} / 2$ methods (A, the maximum diameter of the maximum bleeding layer; $\mathrm{B}$, the diameter of the vertical to $\mathrm{A}$; $\mathrm{C}$, the number of vertical planes multiplied by the thickness of each layer). The GCS and Hemphill ICH scores were calculated. A prognostic evaluation of impaired nerve function was performed according to the Rankin scale score (modified Rankin scale, mRS) after 90 days. A positive outcome was defined as $\mathrm{mRS}<3$ and a poor outcome was defined as $m R S \geq 3$.

Vital signs and biochemical indicators. Fasting blood glucose, white blood cell count and serum sodium were determined. Body temperature, systolic blood pressure and diastolic blood pressure were also measured.

Enzyme-linked immunosorbent assay (ELISA). Venous blood (3 ml) was drawn when fasting and centrifuged for $10 \mathrm{~min}$ at $3,000 \mathrm{rpm}$ to collect plasma. The serum following centrifugation was stored at $-80^{\circ} \mathrm{C}$ in a refrigerator. Copeptin levels were assessed by ELISA. The ELISA kit was purchased from Phoenix Pharmaceuticals (Burlingame, CA, USA).

Statistical analysis. Statistics analyses were carried out using SPSS 19.0 software (SPSS Inc., Chicago, IL, USA). Continuous variables were expressed as the mean \pm standard deviation. An independent samples t-test was used when comparing two groups. The Chi-square test was applied to enumeration data. The prognostic accuracy of copeptin and other prognostic parameters were analyzed with univariate and multivariate logistic regression models. Spearman's Rho was applied in
Table II. Univariate logistic regression analysis of prognostic indicators of impaired nerve function.

\begin{tabular}{lccc}
\hline $\begin{array}{l}\text { Prognostic } \\
\text { indicators }\end{array}$ & OR & $95 \% \mathrm{CI}$ & P-value \\
\hline $\begin{array}{l}\text { White blood } \\
\text { cell count }\end{array}$ & 1.06 & $1.01-1.12$ & 0.003 \\
$\begin{array}{l}\text { Blood glucose } \\
\text { Hemphill score }\end{array}$ & 1.09 & $1.01-1.18$ & 0.002 \\
GCS score & 2.19 & $1.46-3.27$ & 0.000 \\
Hematoma volume & 1.62 & $0.96-2.43$ & 0.001 \\
Copeptin & 1.02 & $1.01-1.04$ & 0.000 \\
& 3.17 & $2.01-4.35$ & 0.003 \\
\hline
\end{tabular}

OR, odds ratio; CI, confidence interval; GCS, Glasgow coma scale.

Table III. Independent prognostic factors for cerebral hemorrhage.

\begin{tabular}{lccr}
\hline Prognostic indicators & OR & $95 \%$ CI & P-value \\
\hline Hemphill score & 1.09 & $0.86-1.27$ & 0.000 \\
GCS score & 1.22 & $0.96-1.43$ & 0.000 \\
Copeptin & 1.28 & $1.05-1.48$ & 0.000 \\
\hline
\end{tabular}

OR, odds ratio; CI, confidence interval; GCS, Glasgow coma scale.

the correlation analysis. $\mathrm{P}<0.05$ was considered to indicate a statistically significant difference.

\section{Results}

Clinical characteristics. Among the $120 \mathrm{ICH}$ patients, there were 76 males and 44 females with ages from 32 to 84 years. 
Table IV. Prognostic indicators for survivors and non-survivors.

\begin{tabular}{|c|c|c|c|c|}
\hline Prognostic indicators & Survivors $(n=96)$ & Non-survivors $(\mathrm{n}=24)$ & Test value & P-value \\
\hline Copeptin (ng/ml) & $3.40 \pm 0.46$ & $4.97 \pm 0.73$ & 1.58 & 0.000 \\
\hline Hematoma volume (ml) & $42.39 \pm 31.16$ & $117.72 \pm 50.66$ & 75.32 & 0.000 \\
\hline GCS score & $12.25 \pm 3.59$ & $4.00 \pm 1.25$ & -8.25 & 0.000 \\
\hline Hemphill score & $1.48 \pm 1.26$ & $4.33 \pm 0.48$ & 2.85 & 0.000 \\
\hline Blood glucose (mM) & $6.39 \pm 2.54$ & $7.59 \pm 1.46$ & 1.21 & 0.030 \\
\hline White blood cell count $\left(\times 10^{12} / 1\right)$ & $8.73 \pm 2.70$ & $14.95 \pm 5.57$ & 6.21 & 0.000 \\
\hline
\end{tabular}

GCS, Glasgow coma scale.

Table V. Univariate logistic regression analysis of the 90-day mortality rate of patients.

\begin{tabular}{lccr}
\hline Prognostic indicators & OR & $95 \%$ CI & P-value \\
\hline $\begin{array}{l}\text { White blood } \\
\text { cell count }\end{array}$ & 1.21 & $1.01-1.43$ & 0.003 \\
GCS score & 0.34 & $0.16-0.72$ & 0.001 \\
Hemphill score & 5.14 & $2.05-8.89$ & 0.000 \\
Hematoma volume & 1.11 & $1.05-1.17$ & 0.000 \\
Copeptin & 5.29 & $3.68-8.03$ & 0.000 \\
\hline
\end{tabular}

OR, odds ratio; CI, confidence interval; GCS, Glasgow coma scale.

Bleeding sites differed among the patients: 96 cases were in the basal ganglia region (80\%), 12 cases were in a lobe of the brain $(10 \%), 6$ cases were in the brain stem (5\%) and 6 cases were in the cerebellum (5\%). The average plasma copeptin level of the $120 \mathrm{ICH}$ patients was $3.71 \pm 0.82 \mathrm{ng} / \mathrm{ml}$ compared with $2.82 \pm 0.36 \mathrm{ng} / \mathrm{ml}$ for the control group of healthy individuals. General clinical data of the ICH patients are listed in Table I.

Copeptin and other prognostic indicators. Copeptin, Hemphill scores, white blood cell count and Glasgow coma scale (GCS) were determined on admission.

The copeptin level correlated positively with hematoma volume $(\mathrm{r}=0.61, \mathrm{P}=0.000)$, Hemphill score $(\mathrm{r}=0.78, \mathrm{P}=0.000)$ and white blood cell count $(\mathrm{r}=0.58, \mathrm{P}=0.000)$, and negatively with GCS score $(\mathrm{r}=-0.79, \mathrm{P}=0.000)$. The average level of copeptin $(3.71 \mathrm{ng} / \mathrm{ml})$ divided the high and low copeptin groups (Table I). Analyses revealed that hematoma volume, GCS score, Hemphill score, mRS score, systolic blood pressure, white blood cell count and blood glucose differed significantly between the two groups; however, there were no significant differences in the other parameters.

Copeptin and prognosis of impaired nerve function. After 90 days, prognosis of impaired nerve function was positive in 48 cases (40\%) and poor in 72 cases (60\%). Plasma copeptin levels were higher at admission in patients with a poor prognosis than in those with a positive prognosis $(4.14 \pm 0.87$ vs. $3.09 \pm 0.30 \mathrm{ng} / \mathrm{ml}, \mathrm{t}=8.001, \mathrm{P}=0.000)$. Univariate logistic regression analysis of prognostic indicators of impaired nerve function revealed that copeptin level, white blood cell count, blood glucose, brain hemorrhage and Hemphill score were prognostic indicators (Table II). Multivariate logistic regression analysis revealed that copeptin level, GCS score and Hemphill score were independent prognostic factors for cerebral hemorrhage (Table III).

Copeptin and mortality rates. During the 90 days of follow-up, 24 patients $(20 \%)$ succumbed. The copeptin level was higher in the non-survivors than in the survivors $(4.97 \pm 0.73$ vs. $3.40 \pm 0.46 \mathrm{ng} / \mathrm{ml}, \mathrm{t}=1.58, \mathrm{P}=0.000)$. Hematoma volume, GCS score, Hemphill score, white blood cell count and blood glucose were significantly different between the non-survivors and survivors (Table IV). No significant differences existed in the other parameters. Univariate logistic regression analysis revealed that the copeptin level, white blood cell count, GCS score, Hemphill score and hematoma volume were valuable for mortality prediction (Table V).

\section{Discussion}

The close correlation between copeptin level and hypothalamicpituiary-adrenal (HPA) axis activation was the basis of the use of copeptin as a prognostic biomarker (13-16). The current study found that the plasma copeptin level increased in patients with acute ICH. In accordance with the Hemphill score and GCS score, the level of copeptin increased with the severity of $\mathrm{ICH}$. Univariate logistic regression analysis indicated that copeptin level, hematoma volume, GCS score, Hemphill score, white blood cell count and blood glucose are independent prognostic indicators for impaired nerve function, 90 days after ICH.

In the acute stage of $\mathrm{ICH}$, the body enters a state of stress, activated by the HPA axis. Then, corticotropin-releasing hormone is secreted by the hypothalamic paraventricular nucleus. AVP is a hypothalamic-stimulating factor in the HPA axis and has a significant synergistic effect with corticotropin-releasing hormone. Together, they promote the anterior pituitary to release adrenocorticotropic hormone and then stimulate the adrenal cortex to produce cortisol. The level of copeptin increased with the severity of stress and at a far quicker pace than that of cortisol in severe stress conditions (15). Copeptin may receive endogenous information through the thalamus, thus respond to the damage accurately. However, its mechanism remains unclear. Cerebral edema in patients with ICH indicates poor prognosis. The copeptin level 
may reflect the brain edema formation and its severity, thus helping to determine the existence of cerebral edema, which may be treated with an AVP receptor antagonist.

A previous study demonstrated that higher levels of copeptin in patients with acute progression of chronic obstructive pulmonary disease (COPD) indicated significantly prolonged hospital stay and intensive care unit treatment (17). The Kaplan-Meier survival curve revealed that copeptin levels were significantly higher in patients with poor long-term prognosis. Katan et al (15) found that the copeptin level was an independent predictor of brain function and mortality rate three months after acute cerebral infarction and it may improve the accuracy of the National Institute of Health Stroke Score (NIHSS) on neurological damage prognosis and mortality prediction and thus further improve the risk stratification of stroke patients. Urwyler et al (18) performed a one-year follow-up based on the above studies and found that copeptin was an independent predictor of brain function and mortality rates one year after cerebral infarction.

Zweifel et al (16) determined the copeptin levels of 40 patients with spontaneous $\mathrm{ICH}$ and the results revealed the prognostic value of copeptin levels in patients with $\mathrm{ICH}$. However, due to small sample volumes, clinical studies with larger sample numbers are required for further validation. If the prognostic value of copeptin in ICH is verified in large-scale cohort studies, particularly in combination with other prognostic indicators, the risk assessment would be improved. In summary, copeptin is expected to become a new prognostic indicator of $\mathrm{ICH}$.

\section{References}

1. Zhao D, Liu J, Wang W, et al: Epidemiological transition of stroke in China: twenty-one-year observational study from the Sino-MONICA-Beijing Project. Stroke 39: 1668-1674, 2008.

2. Johnston SC: Clinical practice. Transient ischemic attack. N Engl J Med 347: 1687-1692, 2002.

3. Delgado P, Alvarez Sabin J, Montaner J, et al: Biological markers in spontaneous intracerebral hemorrhage. Neurologia 22: 448-455, 2007 (In Spanish).

4. Johansson A, Olsson T, Carlberg B, et al: Hypercortisolism after stroke-partly cytokine-mediated? J Neurol Sci 147: 43-47, 1997.
5. Volpi S, Rabadan-Diehl C and Aguilera G: Vasopressinergic regulation of the hypothalamic pituitary adrenal axis and stress adaptation. Stress 7: 75-83, 2004.

6. Alvarez-Sabin J, Delgado P, Abilleira S, et al: Temporal profile of matrix metalloproteinases and their inhibitors after spontaneous intracerebral hemorrhage: relationship to clinical and radiological outcome. Stroke 35: 1316-1322, 2004.

7. Singh RG: The physiology and emerging roles of antidiuretic hormone. Int J Clin Pract 56: 777-782, 2002.

8. Morgenthaler NG, Struck J, Alonso C, et al: Assay for the measurement of copeptin, a stable peptide derived from the precursor of vasopressin. Clin Chem 52: 112-119, 2006.

9. Barat C, Simpson L, Breslow E, et al: Properties of human vasopressin precursor constructs inefficient monomer folding in the absence of copeptin as a potential contributor to diabetes insipidus. Biochemistry 43: 8191-8203, 2004.

10. Jochberger S, Morgenthaler NG, Mayr VD, et al: Copeptin and arginine vasopressin concentrations in critically ill patients. J Clin Endocrinol Metab 91: 4381-4386, 2006.

11. Neuhold S, Huelsmann M, Strunk G, et al: Comparison of copeptin, B-type natriuretic peptide, and amino-terminal proB-type natriuretic peptide in patients with chronic heart failure: prediction of death at different stages of the disease. J Am Coll Cardiol 52: 266-272, 2008

12. Voors AA, von Haehling S, Anker SD, et al: C-terminal provasopressin (copeptin) is a strong prognostic marker in patients with heart failure after an acute myocardial infarction: results from the OPTIMAAL study. Eur Heart J 30: 1187-1194, 2009.

13. Katan M and Christ-Crain M: The stress hormone copeptin: a new prognostic biomarker in acute illness. Swiss Med Wkly 140 w13101, 2010.

14. Katan M, Fluri F, Morgenthaler NG, et al: Copeptin: a novel, independent prognostic marker in patients with ischemic stroke. Ann Neurol 66: 799-808, 2009

15. Katan M, Morgenthaler N, Widmer I, et al: Copeptin, a stable peptide derived from the vasopressin precursor, correlates with the individual stress level. Neuro Endocrinol Lett 29: 341-346, 2008.

16. Zweifel C, Katan M, Schuetz P, et al: Copeptin is associated with mortality and outcome in patients with acute intracerebral hemorrhage. BMC Neurol 10: 34, 2010

17. Stolz D, Christ-Crain M, Morgenthaler NG, et al: Copeptin, c-reactive protein and procalcitonin as prognostic biomarkers in acute exacerbation of COPD. Chest 131: 1058-1067, 2007.

18. Urwyler SA, Schuetz P, Fluri F, et al: Prognostic value of copeptin one-year outcome in patients with acute stroke. Stroke 41: 1564-1567, 2010. 